\title{
Longitudinal study of lung function in coal-miners
}

\author{
RG LOVE, BG MILLER \\ From the Institute of Occupational Medicine, Edinburgh
}

\begin{abstract}
Longitudinal loss of lung function in 1677 coal-miners from five British collieries has been calculated from the results of serial cross-sectional epidemiological surveys and compared with measured concurrent individual respirable dust exposures and partially estimated previous cumulative exposures. Loss of forced expired volume in one second $\left(\mathrm{FEV}_{1}\right)$ over approximately 11 years was found to increase with previous cumulative dust exposure after allowing for the effects of age, height, smoking, and overall colliery differences. This relationship was found to hold with concurrent dust exposure only when colliery differences were ignored. These results confirm by direct measurement inferences drawn indirectly from previous cross-sectional studies of the relationship between $\mathrm{FEV}_{1}$ and dust exposure.
\end{abstract}

Cross-sectional epidemiological surveys of British coal-miners have demonstrated an inverse relationship between forced expired volume in one second $\left(F E V_{1}\right)$ and cumulative exposure to respirable mixed coal-mine dust, independently of the presence of pneumoconiosis, ${ }^{1}$ suggesting that respirable dust exposure might be related to rate of decline of lung function in excess of that attributable to aging and smoking.

This cross-sectional type of analysis has limitations in demonstrating relationships with loss of FEV 1 over time, because all measurements are made on different individuals, at essentially the same time point; the inferences made from such studies concerning loss of $\mathrm{FEV}_{1}$ can therefore only be indirect. A longitudinal study, on the other hand, deals with direct observations of individual men's data at several different times and the inferences made about loss of $\mathrm{FEV}_{1}$ are therefore based on observed losses.

The aim of the present study was to re-examine the findings of Rogan et al $^{1}$ by analysing the observed losses of $\mathrm{FEV}_{1}$ in a group of miners seen in serial cross-sectional epidemiological surveys over a 10 to 12 year period. Individual losses of $F V_{1}$ in men examined in three such surveys during this period have been analysed and compared with individual measured dust exposures during the same period and with partially estimated previous cumulative dust exposure before the study period.

Address for reprint requests: Dr RG Love, Medical Branch, Institute of Occupational Medicine, 8 Roxburgh Place, Edinburgh EH8 9SU.

\section{Methods}

Medical surveys were carried out at about fiveyear intervals at each colliery forming part of the National Coal Board's Pneumoconiosis Field Research between 1957 and 1973. Lung function data from five of these collieries have been examined for the present study. The time between the first and third surveys at these five collieries ranged from 10 to 12 years. The collieries have been identified by the code letters $\mathrm{C}, \mathrm{F}, \mathrm{K}, \mathrm{W}$, and $\mathrm{X}$.

\section{MEDICAL SURVEY MEASUREMENTS}

During each medical survey a short questionnaire of respiratory symptoms and smoking history was administered by a trained clerk ${ }^{2}$ and forced expired volume in one second $\left(\mathrm{FEV}_{1}\right)$ was measured using a modified Gaensler spirometer. ${ }^{3}$ The mean of three technically satisfactory forced expirations, after one practice blow, was used for the analysis. Forced vital capacity (FVC) was also measured at some collieries but since data on FVC were incomplete they have not been analysed here. A full size chest radiograph was taken by a standard technique. Standing height without shoes was also measured to the nearest centimetre.

\section{STUDY POPULATION}

Attendances at the first surveys were over $95 \%$ at all the collieries. Of 6191 men who were seen at the first survey 2025 men attended the second and third surveys. From these were excluded 225 men under 30 years of age at the time of the second survey (in order to exclude younger men who were still growing 
at the first survey). Also excluded were 49 men whose chest radiographs at any of the surveys were thought to show progressive massive fibrosis, ${ }^{4}$ and a further 74 men, whose replies to the questions on smoking at the three surveys were logically inconsistent (for example, smoked at first survey but denied ever smoking at second or third surveys) or who had started smoking during the study period. There remained in the study sample 1677 men.

\section{DUST EXPOSURE MEASUREMENTS}

Beginning between 1953 and 1957, and throughout the period of study, detailed records of each man's type and place of work underground during his working life were maintained. Measurements of airborne respirable dust (mainly particles $<5 \mu \mathrm{m}$ diameter) had been made at these collieries for the same period, as previously described, ${ }^{1}$ and estimates of conditions existing before measurements began were made by assuming similar conditions to those existing during the first 10 years of measurement. On the basis of these measurements and estimates, and the occupational histories, each man's cumulative mixed respirable mine dust exposure during and before the period of study were calculated as described previously. ${ }^{4}$

\section{METHODS OF ANALYSIS}

The change in $\mathrm{FEV}_{1}$ was found by subtracting mean $\mathrm{FEV}_{1}$ at the third survey from that at the first survey. Since the intervening period ranged from about 10 to 12 years at the different collieries, these changes were standardised proportionally to a period of 11 years; the estimated rate of loss of FEV in 11 years, $\triangle F E V_{1}$, was defined as:

$$
\frac{1 \text { st } \mathrm{FEV}_{1}-3 \mathrm{rd} \mathrm{FEV}}{\text { years between surveys }} \times 11
$$

A mean level of $\mathrm{FEV}_{1}$ standardised to five and a half years after the first survey was defined as 1 st $F E V_{1}-$ $\frac{1}{2} \triangle F E V_{1}$. The total of each man's dust exposure for the intervening period was similarly standardised to correspond to an 11-year period-this

Table 1 Characteristics of study population of 1677 miners

\begin{tabular}{lc}
\hline Variable & Mean \\
\hline Age (yr) & $45 \cdot 3$ \\
Height (cm) & $170 \cdot 5$ \\
Dust exposure $\left(\mathrm{gh} / \mathrm{m}^{3}\right)$ & \\
(a) Concurrent & $47 \cdot 2$ \\
(b) Previous & $117 \cdot 0$ \\
FEV level (I) & $3 \cdot 06$ \\
Smoking habits of 1677 miners & 215 \\
Non-smokers & 77 \\
Ex-smokers & 276 \\
Intermittent smokers & 1109 \\
Current smokers & \\
\hline
\end{tabular}

Table 2 FEV 1 levels and losses and dust exposure according to age and smoking habits

\begin{tabular}{|c|c|c|c|c|c|}
\hline \multirow[t]{2}{*}{ Smoking habit } & \multicolumn{5}{|c|}{ Age (years) } \\
\hline & $<39$ & & $40-49$ & $>50$ & All ages \\
\hline \multirow[t]{5}{*}{ Non-smokers } & $\mathbf{n}=$ & 57 & 90 & 68 & 215 \\
\hline & FEV $=$ & 3.67 & $3 \cdot 13$ & $2 \cdot 74$ & $3 \cdot 15$ \\
\hline & $\triangle \mathrm{FEV}=$ & 0.36 & 0.43 & 0.42 & 0.41 \\
\hline & PDE $=$ & 69 & 128 & 143 & 117 \\
\hline & $\mathrm{CDE}=$ & 58 & 50 & 38 & 49 \\
\hline \multirow[t]{5}{*}{ Ex-smokers } & & 13 & 28 & 36 & 77 \\
\hline & & $3 \cdot 63$ & $3 \cdot 17$ & $2 \cdot 86$ & $3 \cdot 10$ \\
\hline & & 0.48 & 0.43 & 0.52 & 0.48 \\
\hline & & 39 & 122 & 133 & 113 \\
\hline & & 47 & 52 & 40 & 45 \\
\hline \multirow[t]{5}{*}{ Intermittent smokers } & & 68 & 109 & 99 & 276 \\
\hline & & $3 \cdot 62$ & $3 \cdot 21$ & $2 \cdot 56$ & 3.08 \\
\hline & & 0.46 & 0.53 & 0.55 & 0.52 \\
\hline & & 67 & 109 & 131 & 107 \\
\hline & & 58 & 46 & 42 & 48 \\
\hline \multirow[t]{5}{*}{ Current smokers } & & 245 & 506 & 358 & 1109 \\
\hline & & 3.66 & 3.06 & $2 \cdot 58$ & 3.03 \\
\hline & & 0.47 & 0.52 & $0 \cdot 59$ & 0.53 \\
\hline & & 57 & 127 & 152 & 120 \\
\hline & & 52 & 50 & 39 & 47 \\
\hline \multirow[t]{5}{*}{ All men } & & 383 & 733 & 561 & 1677 \\
\hline & & 3.64 & 3.09 & $2 \cdot 61$ & 3.06 \\
\hline & & 0.45 & 0.51 & 0.56 & 0.51 \\
\hline & & 60 & 124 & 146 & 117 \\
\hline & & 54 & 50 & 40 & 47 \\
\hline
\end{tabular}

$\mathbf{n}=$ number in each group; FEV $=$ mean of FEV $\mathbf{s}$ at first and third surveys standardised to five and a half years after first survey (1); $\triangle F E V=$ difference between first and third survey $F_{2} V_{2} s$ standardised to 11 years (1); $\mathrm{PDE}=$ previous cumulative respirable dust exposure up to time of first survey $\left(\mathrm{gh} / \mathrm{m}^{3}\right) ; \mathrm{CDE}=$ concurrent dust exposure standardised to 11 years $\left(\mathrm{gh} / \mathrm{m}^{3}\right)$.

quantity is referred to as "concurrent exposure".

Men were classified as non-smokers (that is, less than one cigarette per day for one year), ex-smokers, or smokers on the basis of consistent replies at each survey. A man whose smoking classification was the same at all three surveys was defined as "non-smoker", "ex-smoker", or "current smoker". Of the remainder, men whose classifications were any combination of "current smoker" and "exsmoker" were combined into an "intermittent smoker" group.

Loss of FEV 1 was analysed by fitting to $\triangle F E_{1}$ sequential multiple linear regression models in which the explanatory variables were age, height, smoking category, standardised $\mathrm{FEV}_{1}$ level, and concurrent and previous dust exposures. Differences in loss of $\mathrm{FEV}_{1}$ attributable only to the colliery in which the man was working were also included in some analyses.

\section{Results}

Details of the study population of 1677 men are given in table 1. Mean losses of $\mathrm{FEV}_{1}$ in men grouped according to age and smoking habits are set out in table 2, which also includes details of concurrent and previous dust exposures. With the minor exception of the ex-smoking group, whose 
Table 3 Mean cumulative dust exposures $\left(\mathrm{gh} / \mathrm{m}^{3}\right)$ for men at each colliery. Ranges of observed values shown in brackets

\begin{tabular}{|c|c|c|c|c|}
\hline Colliery & Number of men & Previous exposures & Conch & urrent exposures \\
\hline C & 395 & $69 \quad(1 \cdot 3-169)$ & 40 & $(5 \cdot 0-89)$ \\
\hline $\mathrm{F}$ & 237 & $235 \quad(1 \cdot 3-628)$ & 59 & $(8 \cdot 6-160)$ \\
\hline $\mathbf{K}$ & 400 & $103(7 \cdot 4-325)$ & 43 & $(7 \cdot 4-99)$ \\
\hline W & 238 & $116 \quad(3 \cdot 5-338)$ & 37 & $(3 \cdot 7-99)$ \\
\hline $\mathbf{x}$ & 407 & $110 \quad(4 \cdot 8-247)$ & 58 & $(7 \cdot 1-120)$ \\
\hline Total & 1677 & $117 \cdot 0$ & $47 \cdot 2$ & \\
\hline
\end{tabular}

numbers are fairly small, it is clear that loss of FEV 1 increases with age. Previous dust exposure, which is the summation of products of time worked and dust concentration levels, also rises with age. Concurrent dust exposure, on the other hand, falls with age, probably because older men tend to move away from the relatively dusty jobs at the coalface to elsewhere underground. There is also a clear indication of increased loss of $F E V_{1}$ with smoking habit. Ex-smokers' losses tended to fall between those of non-smokers and smokers. Intermittent and current smokers appear to have very similar losses; by definition, all the "intermittent" smokers were smoking at some point during the study period.

Colliery average concurrent and previous dust exposures are shown in table 3 , the previous cumulative exposures being considerably greater than the concurrent exposures.

Multiple regression analysis showed that age, height, and smoking each made a strong contribution to explaining loss of $F E V_{1}$. There were also systematic differences in loss of $\mathrm{FEV}_{1}$ between collieries. After adjustment for these factors, rate of loss of $\mathrm{FEV}_{1}$ was found to increase significantly with increasing previous dust exposure. There was no evidence that the slope of the regression of $\triangle F E V_{1}$ on previous dust exposure varied between

Table 4 Regression model for loss of FEV (litres). $R^{2}=6 \cdot 1 \%$. Residual $S D=0.364 l$

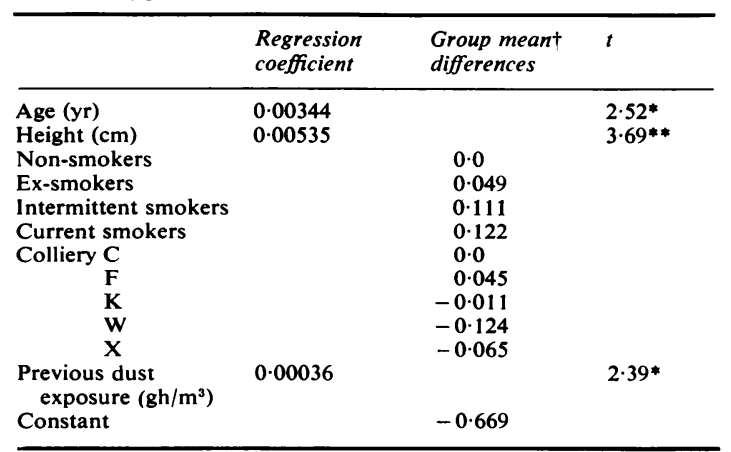

These figures represent the mean differences expected for each smoking or colliery group relative to non-smokers and colliery $\mathbf{C}$ respectively; ${ }^{*} \mathrm{p}<0.05 ;{ }^{* *} \mathrm{p}<0.001$. collieries. Regression coefficients from the analysis including both mean colliery differences and previous dust exposure are shown in table 4.

In studies of this kind an inverse relationship is to be expected between rate of loss of FEV 1 and FEV 1 level. ${ }^{5}$ This effect was observed in the present data but the inclusion of standardised $\mathrm{FEV}_{1}$ as an explanatory variable did not seriously effect the magnitude or statistical significance of the estimated relationship between loss of $\mathrm{FEV}_{1}$ and previous dust exposure.

Tests of the equality between the smoking categories of the regression coefficients of $\triangle F E V_{1}$ on age, height, and $\mathrm{FEV}_{1}$ level were carried out. None of these proved significant, and it was concluded there was no evidence that non-parallel regressions need be fitted.

Table 5 Main effects of occupational and nonoccupational factors on loss of FEV $\left({ }^{*}\right.$ based on estimates in table 4)

\begin{tabular}{|c|c|c|}
\hline \multirow{2}{*}{$\begin{array}{l}\text { Factor } \\
\text { Previous dust exposure }\end{array}$} & \multicolumn{2}{|c|}{$\begin{array}{l}\text { Predicted loss of } F E V_{1} \\
\text { over } 11 \text { years }(S E)^{*} \\
(\mathrm{ml})\end{array}$} \\
\hline & & \\
\hline Average observed $\left(117 \mathrm{gh} / \mathrm{m}^{3}\right)$ & 42 & (15) \\
\hline Maximum observed $\left(628 \mathrm{gh} / \mathrm{m}^{3}\right)$ & 223 & (79) \\
\hline $\begin{array}{l}\text { Maximum likely for a working life under } \\
\text { current conditions in British coal-mines } \\
\left(245 \mathrm{gh} / \mathrm{m}^{3}\right)\end{array}$ & 87 & (30) \\
\hline $\begin{array}{l}\text { Difference between collieries with highest } \\
\text { and lowest loss of FEV }\end{array}$ & 169 & (36) \\
\hline $\begin{array}{l}\text { Smoking: difference between current and } \\
\text { non-smokers }\end{array}$ & 122 & (27) \\
\hline Age difference of 30 years & 103 & (41) \\
\hline
\end{tabular}

Further analyses were performed replacing previous with concurrent dust exposure. Loss of $\mathrm{FEV}_{1}$ was found to be positively related to concurrent dust exposure only if colliery differences were ignored.

Inclusion of all the factors shown in table 4 accounted for just over $6 \%$ of the total variation $\left(R^{2}\right)$ in loss of $F E V_{1}$, the remainder being unexplained. This was typical of all other similar regression analyses carried out, none of them explaining more than $7 \%$ of the total variation.

Predicted losses of FEV 1 over 11 years shown in table 5 are based on results from the analysis summarised in table 4. These figures are estimates of responses that might be expected on average in miners who have experienced the levels of factors indicated, and the standard errors refer to such estimates of average responses. The high level of residual variability in the data, referred to above, implies that the average predicted response is a poor guide to the likely response of an individual miner. For instance, the predicted response, from 
table 4, for an individual non-smoker from colliery $C$, aged 45 years, $170 \mathrm{~cm}$ tall, and with $120 \mathrm{gh} / \mathrm{m}^{3}$ previous exposure would be a loss of $439 \mathrm{ml} \mathrm{FEV}_{1}$ over 11 years. The $95 \%$ confidence interval for the prediction of this individual's response ranges from a gain of 280 to a loss of $1100 \mathrm{ml}$.

Table 5 shows that exposure to the average level of dust recorded for the 1677 men studied (117 $\mathrm{gh} / \mathrm{m}^{3}$ ) is associated with about $40 \mathrm{ml}$ loss in $\mathrm{FEV}_{1}$ over the subsequent 11 years. The highest previous exposure occurring in our data was $628 \mathrm{gh} / \mathrm{m}^{3}$, and this would be associated with $220 \mathrm{ml} \mathrm{FEV} 1$ loss over 11 years. Current regulations governing levels of airborne dust in British coal-mines stipulate that the highest average concentration in the return airway from the coalface must not exceed $7 \mathrm{mg} / \mathrm{m}^{3}$. On this basis the maximum lifetime exposure for miners entering the industry since 1977 is not likely to exceed $245 \mathrm{gh} / \mathrm{m}^{3}$. Our results indicate that such an exposure would, on average, result in an 87 $\mathrm{ml}$ loss of $\mathrm{FEV}_{1}$ during the subsequent 11 years.

\section{Discussion}

Data from serial cross-sectional medical surveys of 1677 working miners have been examined to compare decline in lung function, assessed by the loss of FEV 1 , over an approximately 11 -year period, with measured concurrent and partially estimated previous dust exposures. Loss of $\mathrm{FEV}_{1}$ was found to be related to age, height, and smoking habits, and to the cumulative lifetime exposure to mixed coalmine dust occurring before the study period. The results confirm that longitudinal loss of lung function increases with exposure to coal-mine dust, an effect previously suggested by the cross-sectional study of Rogan et al, ${ }^{1}$ in which level of $\mathrm{FEV}_{1}$ was found to be inversely related to dust exposure. The magnitude of the predicted effect of the average exposure to dust on rate of loss of $F E V_{1}$ appeared to be about one-third of the average loss attributable to smoking, though the predicted mean effect at high dust exposures was similar to that of smoking and could be of clinical importance. By its very nature the study population only included men who remained at work in the collieries during the period of study, and it is not known to what extent possible selfselection of men out of the industry might have influenced the apparent size of the dust and other effects on loss of FEV 1 . If men had left the industry before and during the study because of respiratory ill health, then it is likely that the average rate of loss of $F E V_{1}$, has been underestimated. A subsequent study has been undertaken to follow-up men who have left the industry and the results will be reported when it has been completed.
Because all the men in the study remained as working miners, we should expect their loss of FEV over the study period to be affected by all the exposure up to the end of the study (although exposures experienced in the later period obviously could not have influenced the rates of loss in an earlier period). There are difficulties in attempting to ascertain the time at which an exposure has an effect on lung function. The previous dust exposures are essentially the product of time worked and the dust concentrations prevailing during those periods. Some degree of correlation is likely between these concentrations and those experienced during the study period, at least partly because the average dust conditions within one mine often remain reasonbly stable over periods of time. A comparison of the previous and concurrent dust exposures in table 3 suggests that some correlation is present.

The apparent relationship between loss of $\mathrm{FEV}_{1}$ and concurrent dust exposure may be the result in part of some such correlation. The fact that this effect was not seen when colliery differences were included in the analysis supports this suggestion. The differences between collieries may result from a number of factors-such as concentration of dust and its mineral composition, regional and climatic variation-but these factors cannot be separated in the analysis. However, the relationship between loss of $\mathrm{FEV}_{1}$ and previous dust exposure was apparent even after adjustment for these colliery differences.

It should be noted that a large part of the total variation of loss of $\mathrm{FEV}_{\mathbf{1}}$ was unexplained and that even the best fitting statistical model accounted for only about $7 \%$ of the variation. Measurement error was likely to have contributed to the variation even though the measurements at all the surveys were made by technicians trained and tested for reproducibility and comparability, using the same two identical spirometers for all measurements. Furthermore, individuals are likely to show shortterm variations in $\mathrm{FEV}_{1}$ as a result of such factors as temporary illness, circadian changes, and variations in effort and technique. It is likely that this apparently large short-term variation represents at least in part a real biological variability which should be distinguished in studies such as these from chronic long-term, presumably irreversible, loss of lung function. Large unexplained variation of loss of $\mathrm{FEV}_{1}$ in longitudinal studies has been found by other workers. ${ }^{56}$

The pathological basis of this loss of $\mathrm{FEV}_{1}$ has not been studied in this work. Men with progressive massive fibrosis were excluded from the study, and although men with simple pneumoconiosis were not excluded, there is no evidence that this radiological abnormality is associated with reduced 
$\mathrm{FEV}_{1}$ after allowing for the direct effects of dust exposure. ${ }^{17}$ The loss of $\mathrm{FEV}_{1}$ was likely to have been the result of chronic airflow obstruction, probably caused by varying combinations of bronchial disease and emphysema. However, the obstructive nature of the loss related to dust exposure has not been established conclusively by this study.

We would like to acknowledge the work of MD Attfield who had begun a previous analysis of some of these data. We would also like to thank Dr CA Soutar and Dr M Jacobsen for helpful and extensive criticisms and comments.

\section{References}

${ }^{1}$ Rogan JM, Attfield MD, Jacobsen M, Rae S, Walker DD, Walton WH. Role of dust in the working environment in development of chronic bronchitis in British coal- miners. Br J Ind Med 1973;30:217-26.

${ }^{2}$ Rogan JM, Ashford JR, Chapman PJ, Duffield DP, Fay JWJ, Rae S. Pneumoconiosis and respiratory symptoms in miners at eight collieries. Br Med J 1961; 1:1337-42.

${ }^{3}$ McKerrow CB, McDermott M, Gilson JC. A spirometer for measuring the forced expiratory volume with a simple calibrating device. Lancet 1960;1:149-51.

4 Jacobsen M, Burns J, Attfield MD. Smoking and coalworkers' pneumoconiosis. In: Walton WH, ed. Inhaled particles IV. Old Woking: Unwin Bros, 1977:759-72.

${ }^{5}$ Fletcher C, Peto R, Tinker C, Speizer FE. The natural history of chronic bronchitis and emphysema. An eightyear study of early chronic obstructive lung disease in working men in London. Oxford: Oxford University Press, 1976.

${ }^{6}$ Berry G, McKerrow CB, Molyneux MKB, Rossiter CE, Tombleson JBL. A study of the acute and chronic changes in ventilatory capacity of workers in Lancashire cotton mills. Br J Ind Med 1973;30:25-36.

${ }^{7}$ Hankinson JL, Reger RB, Morgan WKC. Maximal expiratory flows in coal miners. Am Rev Respir Dis 1977;116:175-80. 